\title{
Pengembangan Media Pembelajaran Interaktif Berbantuan Swishmax-4 pada Materi Lingkaran
}

\author{
Komarudin $^{1 *)}$, Agus Pahrudin ${ }^{2}$, \& Vera Nurmalia ${ }^{3}$ \\ 1, 2, ${ }^{3}$ Universitas Islam Negeri Raden Intan Lampung, Bandar Lampung, Indonesia
}

\section{INFO ARTICLES}

Article History:

Received: 29-06-2021

Revised: 30-06-2021

Approved: 30-06-2021

Publish Online: 30-06-2021

\section{Key Words:}

Interactive Learning Media; Swishmax-4; The ADDIE Development Model;

\section{c) (i) (2)} under a Creative Commons AttributionShareAlike 4.0 International License.

\begin{abstract}
Learning media is needed to help facilitate the mathematical learning process. The learning media prepared by educators makes students more active. In this study aims to develop interactive learning media rocky Swishmax-4 on circular material. The type of research used by researchers is Research and development $(R \& D)$ using addie model. The results showed interactive mathematical learning media in the form of Swishmax-4 assisted learning videos that refer to the modified research and development design of the ADDIE development model. Expert validation of developed learning media obtains a "valid" or usable category. In addition, students' response to learning media developed from both small-scale class tests and large-scale classroom tests both have "Very Interesting" criteria and the results of media effectiveness tests can be known that the average value of $N$-Gain falls into the category of "Medium", meaning that the learning media developed has a category of moderate effectiveness if applied in learning
\end{abstract}

\begin{abstract}
Abstrak: Media pembelajaran dibutuhkan untuk membantu memudahkan proses pembelajaran matematika. Adapun media pembelajaran yang disiapkan pendidik membuat peserta didik akan lebih aktif. Pada penelitian ini bertujuan untuk mengembangkan media pembelajaran interaktif berbatuan Swishmax-4 pada materi lingkaran. Jenis Penelitian yang digunakan oleh peneliti adalah Research and development (R\&D) dengan menggunakan model ADDIE. Hasil penelitian menunjukkan media pembelajaran matematika interaktif berupa video pembelajaran berbantuan Swishmax-4 yang mengacu pada rancangan penelitian dan pengembangan yang dimodifikasi dari model pengembangan ADDIE. Hasil validasi ahli terhadap media pembelajaran yang dikembangkan memperoleh kategori "valid" atau layak digunakan. Selain itu, respon mahasiswa terhadap media pembelajaran yang dikembangkan baik dari uji kelas skala kecil maupun uji kelas skala besar keduanya memiliki kriteria "Sangat Menarik" dan hasil uji keefektifitas media dapat diketahui bahwa nilai rata-rata N-Gain termasuk dalam kategori "Sedang", artinya media pembelajaran yang dikembangkan memiliki kategori efektifitas sedang jika diterapkan di dalam pembelajaran.
\end{abstract}

Correspondence Address: Jalan Prof. Dr. Hamka. Perum Golf Asri Blok C-51 Sukarame, Bandar Lampung, 35131, Indonesia; e-mail: komarudin@radenintan.ac.id

How to Cite (APA 6 $^{\text {th }}$ Style): Komarudin, K., Pahrudin, A., \& Nurmalia, V. (2021). Pengembangan Media Pembelajaran Interaktif Berbantuan Swishmax-4 pada Materi Lingkaran. JKPM (Jurnal Kajian Pendidikan Matematika), 6(2): 319-326

Copyright: 2021 Komarudin Komarudin, Agus Pahrudin, Vera Nurmalia

Competing Interests Disclosures: The authors declare that they have no significant competing financial, professional or personal interests that might have influenced the performance or presentation of the work described in this manuscript. 


\section{PENDAHULUAN}

Kualitas pendidikan menjadi perhatian utama (main concern) bangsa-bangsa didunia (Supriyadi, 2016). Sejatinya, karena pentingnya pendidikan yang berkualitas sebagai pembentuk sumber daya manusia yang berkualitas (Izzatul Mufidah, 2014; Muhtadi, 2016). Selain itu, pendidikan akan menentukan kualitas orang-orang yang menjalankan roda hukum serta mengurusi ekonomi suatu bangsa yang keduanya merupakan salah satu pilar utama kemajuan bangsa (Efiani, 2014; Suryadi, 2017). Perkembangan dunia pendidikan selalu beriringan dengan perkembangan teknologi (IPTEK) (Azmi, 2016). Penggunaan teknologi dalam pembelajaran yaitu pemanfaatan sumber daya teknologi sebagai media dalam proses pembelajaran (Ismaniati, 2010; Suryadi, 2017). Yang mana, dibutuhkannya pengembangan media pembelajaran yang sesuai dengan kemajuan teknologi dan informasi menimbang media pembelajaran yang sering digunakan saat ini masih sebatas pada buku cetak (Rodiawati \& Komarudin, 2018).

Berbicara tentang ilmu pengetahuan dan pembelajaran, mata pelajaran yang sangat berperan terhadap perkembangan zaman adalah mata pelajaran matematika. Karena matematika menjadi penemu dan perkembangan ilmu yang lain (R. W. Y. Putra \& Anggraini, 2016). Matematika harus terus ditingkatkan hingga mencapai taraf kualitas terbaik (Rizkiah dkk., 2018). Matematika merupakan cabang ilmu pengetahuan eksak yang melatih peserta didik agar dapat berfikir secara logis, analitis, sistematis, kritis dan kreatif, serta melatih kemampuan bekerja sama (Wahyuningsih \& Rezeki, 2013). Selain itu, matematika memiliki tujuan pembelajaran yakni dapat diterapkannya didalam kehidupan sehari-hari dan didalam ilmu pengetahuan lainnya dengan tepat, demi terbentuknya sumber daya manusia yang berkualitas (Rodiawati \& Komarudin, 2018). Tetapi fakta aktual menunjukkan bahwa hasil belajar siswa masih relatif rendah karena anggapa bahwa matematika merupakan mata pelajaran yang sangat sulit (Aditya, 2016; Anggraeni \& Wasitohadi, 2014; Siregar, 2013).

Salah satu media yang dapat digunakan didalam proses pembelajaran yaitu aplikasi Swishmax. Swishmax adalah suatu program pembuat grafis animasi, yang dimana animasi yang dihasilkan berupa animasi flash (Rimadhona, 2010; Shodikin, 2017). Namun disamping hal itu, Swishmax dapat digunakan untuk membuat suatu materi pembelajaran interaktif yang bervariasi dan menarik dengan berupa animasi dengan teks, gambar, grafik dan suara dengan mudah dan cepat (F. G. Putra, 2018; Wagiran, 2008). Kelebihan Swishmax lainnya yaitu Swishmax dapat ditayangkan ulang karena hasil produknya dapat berupa suatu video pembelajaran yang dapat dipercepat atau diperlambat ataupun diputar berulang kali sesuai kebutuhan hingga peserta didik memahami materi yang disajikan (F. G. Putra, 2018). Untuk itu, penggunaan Swishmax sebagai media dalam pembelajaran matematika dapat membuat proses pembelajaran yang lebih bervariasi dan menarik peserta didik untuk lebih semangat dalam belajar, serta dapat meningkatkan pemahaman siswa lebih baik lagi dari sebelumnya yakni sebelum menggunakan media pembelajaran Swishmax.

Penelitian tentang pengembangan modul matematika telah beberapa kali dilakukan, diantaranya berbasis STEM (Utami dkk., 2018), berbasis kontekstual terintegrasi ilmu ke-Islaman (Kurniati, 2016), berbasis discovery learning berbantuan flipbook maker (Haryanti \& Saputro, 2016), terintegrasi nilai-nilai keislaman (Ekawati dkk., 2019), berbasis etnomatematika (Finariyati dkk., 2020; Mardiah \& Rinaldi, 2018; Rohmaini dkk., 2020), berbasis problem solving pada materi vector (Ariskasari \& Pratiwi, 2019), dengan pendekatan metakognitif (Zulfikar \& Tamrin, 2019), dan pengembangan modul matematika untuk mengukur kemampuan berpikir kreatif siswa (Anggoro, 2015). Adapun kebaruan terletak pada modul pembelajaran interaktif berbantuan Swishmax-4 khususnya pada Materi Lingkaran, karena pada penelitian sebelumnya belum terdapat pengembangan modul pembelajaran interaktif berbantuan. Sehingga tujuan dilaksanakan pengembangan ini untuk mengembangkan media pembelajaran interaktif berbatuan Swishmax-4 pada materi lingkaran. 


\section{METODE}

Jenis Penelitian yang digunakan oleh peneliti adalah Research and development (R\&D). Penelitian ini menggunakan prosedur penelitian model ADDIE (Analysis, Design, Development, Implementation dan Evaluation) (Branch, 2009; Komarudin dkk., 2020; Vejvodova, 2015). Model ADDIE ialah media pembelajaran berupa video pembelajaran dirancang dengan menggunakan Swishmax-4. Berikut Diagram Tahap model ADDIE disajikan dalam Gambar 1.

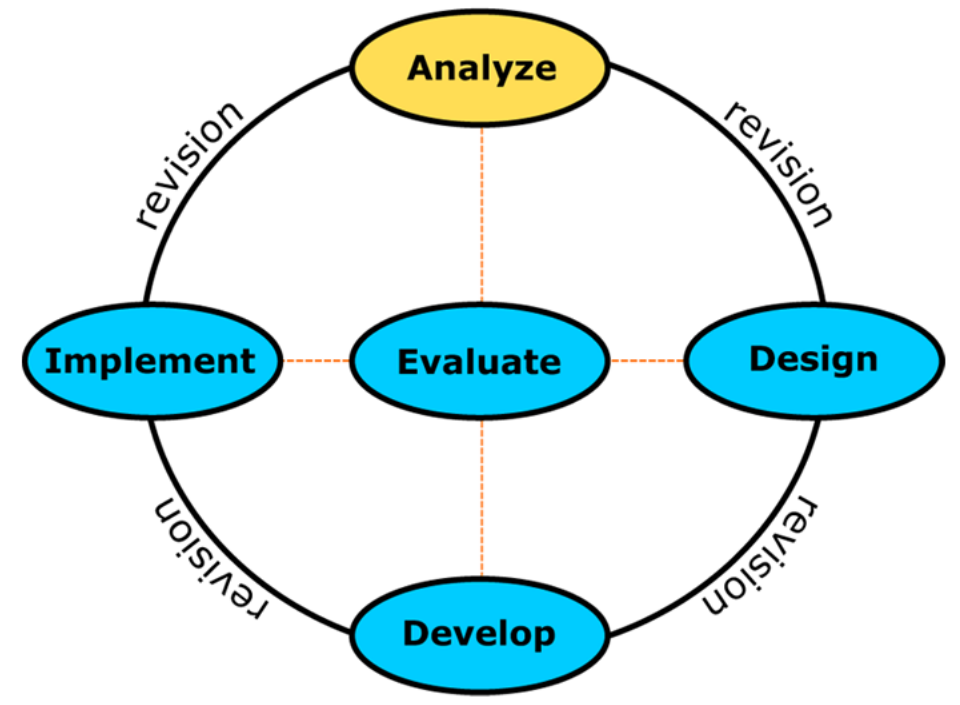

\section{Gambar 1. Diagram Tahap Model ADDIE}

Teknik pengumpulan data dalam penelitian ini antara lain sebagai berikut: wawancara, angket (kuesioner) dan tes. Tes yang disusun merupakan tes berbentuk soal essay yang telah diuji instrument soal sebelumnya. Pada tahap ini dilakukan dua kali tes berupa pre-test dan post-test. Teknik analisis data yang digunakan yang pertama yaitu analisis data validasi ahli.

\section{HASIL}

Penelitian dan pengembangan yang dilakukan di Jurusan Pendidikan Matematika UIN Raden Intan Lampung menghasilkan video pembelajaran Matematika Interaktif dengan berbantuan Swishmax-4 yang telah divalidasi oleh para ahli, serta diujicobakan kepada peserta didik. Langkah-langkah yang digunakan untuk mengembangkan video pembelajaran matematika interaktif ini antara lain:

1. Analyze

Analisis dilakukan sebagai acuan untuk mengembangkan video pembelajaran. Hasil Analisis mahasiswa yang dilakukan meliputi:
a) Analisis Keadaan
b) Analisis Kebutuhan
c) Analisis karakteristik peserta didik.

2. Design

Setelah evaluasi, selanjutnya dilakukan tahap design dengan hasil sebagai berikut:
a. Penyusunan Kerangka Video Pembelajaran
b. Perancangan Penyajian Materi
c. Perancangan Instrumen. 
3. Development

Tahap development media pembelajaran dibuat sesuai rancangan pada tahap design, sebagai berikut:

a. Pembuatan Media (Video Pembelajaran)

1) Bagian isi materi

2) Bagian penutup

b. Hasil Evaluasi Validator

1) Evaluasi ahli media

a) Evaluasi ahli media I

b) Evaluasi ahli media II

c) Evaluasi ahli media III

2) Evaluasi ahli materi

a) Evaluasi ahli materi I

b) Evaluasi ahli materi II

c) Evaluasi ahli materi III

c. Hasil Penilaian Angket Validasi Tahap I

1. Penilaian Angket Validasi Ahli Materi

2. Penilaian angket validasi ahli media

3. Revisi Pembuatan Media

4. Hasil penilaian Angket Validasi tahap 2

5. Penilaian Angket Validasi Ahli Materi

6. Penilaian Angket Validasi Ahli Media

Uji kemenarikan media pembelajaran dilakukan pada melalui 2 tahap, yaitu uji skala kecil dilakukan terhadap 10 responden dan sekala besar 30 responden. Data hasil uji coba respon skala kecil dan besar dapat dilihat pada Gambar 2.

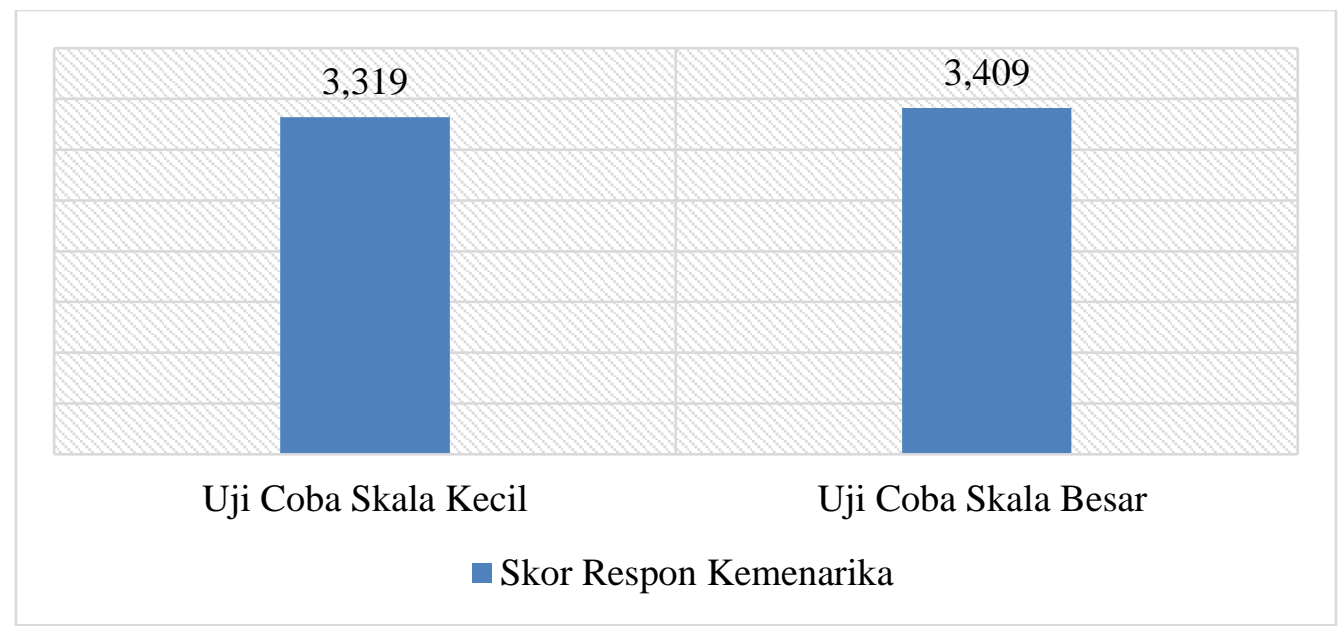

4. Implementation

\section{Gambar 2. Hasil Uji Coba Skala Kecil dan Skala Besar}

Setelah produk dinyatakan valid layak digunakan dan menarik, selanjutnya pada tahap implementasi diberikan uji tes yaitu pre-test dan post-test kepada mahasiswa pendidikan matematika UIN Raden Intan Lampung. Sebelum pre-test dan post-test dilakukan, instrumen soal di uji terlebih dahulu selain kelas sampel yaitu kelas uji coba dengan jumlah mahasiswa uji coba 30 mahasiswa.

1) Uji Validitas

2) Uji Reliabititas. 
3) Uji Tingkat Kesukaran

4) Uji Daya Pembeda.

Tabel 1. Hasil Perhitungan Pre-test dan Post-test

\begin{tabular}{cccccc}
\hline & $\mathrm{N}$ & Skor Ideal & Skor Minimum & Skor Maksimum & $\bar{x}$ \\
\hline Pre-test & 30 & 100 & 15 & 65 & 39 \\
Post-test & 30 & 100 & 55 & 90 & 75 \\
\hline
\end{tabular}

Sumber: diolah dari data penelitian, 2021

Berdasarkan data yang diperoleh pada Tabel 1, dapat dilihat perolehan skor minimum, skor maksimum, dan $\bar{x}$ dari hasil uji pre-test dan post-test. Hasil skor minimum dari pre-test adalah 15 dan skor minimum dari post-test adalah 55. Skor maksimum dari pre-test adalah 65 dan skor maksimum dari post-test adalah 90 . Nilai $\bar{x}$ pada pre-test 39 dan pada post-test adalah 75 . Rekapitulasi nilai $N$-gain dapat dilihat pada Tabel 2 sebagai berikut:

Tabel 2. Rekapitulasi Nilai $N$-gain

\begin{tabular}{cccccc}
\hline & $\mathrm{N}$ & Skor Ideal & Skor Minimum & Skor Maksimum & $\bar{x}$ \\
\hline III-H & 100 & 100 & 0.27 & 0.79 & 0.59 \\
\hline
\end{tabular}

Sumber: diolah dari data penelitian, 2021

Tabel 2 dapat dilihat nilai minimum, nilai maksimum dan rata-rata $N$-Gain. Hasil nilai minimum pada pre-test dan post-test adalah 0.27 dan hasil nilai maksimum adalah 0.79 . Nilai rata-rata $N$-Gain pada pre-test dan post-test adalah 0.59 dan termasuk dalam kategori efektifitas "sedang". Sehingga media pembelajaran dapat digunakan dalam pembelajaran matematika, khususnya materi lingkaran.

5. Tahap evaluation (evaluasi)

Tahap evaluasi dalam penelitian ini dapat diterapkan di setiap tahap ADDIE. Evaluasi dilakukan untuk menganalisis data hasil penelitian yang diperoleh yaitu analisis kebutuhan peserta didik, penyusunan desain, kevalidan produk dari para ahli, hasil angket respon peserta didik serta keefektifan produk saat digunakan dalam pembelajaran.

\section{PEMBAHASAN}

Penelitian dan Pengembangan perangkat pembelajaran yang telah dilakukan menggunakan model pengembangan ADDIE (analysis, design, development, implementation, evaluation). Dalam proses pengembangan video pembelajaran berbantuan Swishmax-4 ini evaluasi selalu dilakukan pada keempat tahap pengembangan. Setelah dilakukan evaluasi pada tahap analisis selanjutnya adalah tahap design atau perancangan. Tahap selanjutnya yaitu pengembangan atau development. Tahap ini merupakan tahap pembuatan perangkat pembelajaran dan proses validasi atau tahap uji coba kelayakan produk. Produk yang sudah selesai selanjutnya dievaluasi oleh para pakar dan praktisi pendidikan sebagai validator yang terdiri dari ahli materi dan ahli media. Hasil uji kemenarikan Video Pembelajaran dapat dilihat dari angket respon mahasiswa yang sudah dibagikan dan mendapatkan hasil rata-rata uji skala kecil sebesar 3.319 pada kriteria "Sangat Menarik" dan hasil rata-rata penilaian pada uji skala besar yaitu sebesar 3.409 pada kriteria "Sangat Menarik". Berdasarkan hasil tersebut dapat ditarik kesimpulan bahwa media pembelajaran interaktif berbantuan Swishmax-4 yang dikembangkan telah memenuhi aspek kemenarikan sehingga layak untuk diimplementasikan kepada mahasiswa pendidikan matematika UIN Raden Intan Lampung. Berdasarkan hasil yang diperoleh dari uji efektifitas dapat diketahui bahwa nilai rata-rata $N$-Gain $(g) \geq 0,59$ termasuk 
kategori "Sedang", artinya media pembelajaran yang dikembangkan memiliki kategori efektifitas sedang jika diterapkan di dalam pembelajaran. Tahap berikutnya adalah evaluasi dimana tahap ini fleksibel dapat dilakukan disemua tahap ADDIE. Evaluasi memegang penting dalam mengevaluasi kualitas dan efektifitas produk yang dikembangkan dan diujicobakan kepada mahasiswa.

Kelebihan media pembelajaran interaktif berbantuan Swishmax-4 yang telah dikembangkan yaitu mudah diaplikasikan karena dapat dibuka di handphone android maupun ios dan dapat dibuka dilaptop. Aplikasi Swishmax-4 dapat diakses secara offline sehingga tidak menjadi halangan ketika pengguna kehabisan paket data namun ingin menggunakan media. Selaian itu, aplikasi Swishmax-4 sangat mudah digunakan terutama untuk pemula karna koleksi script dan effectnya mudah dicerna dan dimodifikasi, cocok digunakan untuk keperluan pembuatan presentasi, animasi, website serta bisa dijadikan tambahan untuk pembutaan video editing. Kekurangan pada pengembangan media pembelajaran matematika interaktif berbantuan Swishmax-4 ini yaitu pada aplikasi Swishmax-4 belum menyediakan pengoperasian simbolsimbol aljabar sehingga peneliti mengembangkan media yang berbentuk aljabar dengan cara menjadikannya sebuah foto terlebih dahulu kemudian memasukannya kedalam aplikasi Swishmax-4 dan dikembangkan ke dalam produk yang dibuat. Selain itu media pembelajaran yang dikembangkan masih sebatas materi lingkaran pada mata kuliah geometri analitik bidang yang terdiri dari lima indikator pencapaian sehingga perlu dikembangkan lebih luas lagi. Berdasarkan pemaparan kelebihan, kekurangan yang peneliti lakukan serta hasil penelitian yang selaras sebelumnya dapat di yakinkan bahwa Software Swishmax-4 dapat dimanfaatkan untuk pembuatan media pembelajaran interaktif baik untuk diterapkan dari tingkat SMP, SMA ataupun Perguruan Tinggi. selain itu pentingnya suatu media pembelajaran berbantuan teknologi untuk dimanfaatkan dalam proses pembelajaran lebih dapat menarik pelajar untuk lebih giat dan termotivasi dalam proses pembelajaran.

Secara umum hasil dan pembahasan penelitian ini, melengkapi hasil penelitian dilakukan oleh Aminah \& Haryoto (2018); Charissudin (2021); F. G. Putra (2018); Ratnawati \& Fitri (2020) yang hanya mengembangkan media pembelajaran interaktif dengan berbantuan Swishmax-4 dengan kategori "sangat valid". Tetapi dalam penelitian ini, dilakukan penelitian sampai pada uji kemenarikan dan efektifitas media pembelajaran. Tidak hanya sangat valid tetapi juga sangat menarik dan efektif digunakan sebagai media pembelajaran matematika.

\section{SIMPULAN}

Berdasarkan hasil dan pembahasan dapat disimpulkan bahwa pengembangan media pembelajaran matematika interaktif berupa video pembelajaran berbantuan Swishmax-4 yang mengacu pada rancangan penelitian dan pengembangan yang dimodifikasi dari model pengembangan ADDIE. Hasil validasi ahli terhadap media pembelajaran yang dikembangkan memperoleh kategori "valid" atau layak digunakan. Selain itu, respon mahasiswa terhadap media pembelajaran yang dikembangkan baik dari uji kelas skala kecil maupun uji kelas skala besar keduanya memiliki kriteria "Sangat Menarik" dan hasil uji keefektifitas media dapat diketahui bahwa nilai rata-rata $N$-Gain termasuk dalam kategori "Sedang", artinya media pembelajaran yang dikembangkan memiliki kategori efektifitas sedang jika diterapkan di dalam pembelajaran.

Berdasarkan yang telah dilakukan maka ada beberapa saran yaitu media pembelajaran yang dikembangkan masih perlu di maksimalkan lagi agar mencapai efektifitas tinggi, media pembelajaran yang dikembangkan dapat digunakan kampus lain, dan media pembelajaran matematika interaktif berbantuan Swishmax-4 yang dikembangkan masih pada pokok materi Lingkaran, sehingga diharapkan agar media pembelajaran matematika interaktif berbantuan Swishmax-4 dapat dikembangkan dengan materi yang lebih luas. 


\section{DAFTAR RUJUKAN}

Aditya, D. Y. (2016). Pengaruh Penerapan Metode Pembelajaran Resitasi terhadap Hasil Belajar Matematika Siswa. SAP (Susunan Artikel Pendidikan), 1(2).

Aminah, A. N., \& Haryoto, D. (2018). Pengembangan Media Pembelajaran Berbantuan Swishmax 4 untuk Membantu Siswa dalam Menganalisis Besaranbesaran Fisis pada Gerak Lurus. Jurnal Riset Pendidikan Fisika, 3(2), 20-26.

Anggoro, B. S. (2015). Pengembangan Modul Matematika Dengan Strategi Problem Solvin Guntuk Mengukur Tingkat Kemampuan Berpikir Kreatif Matematis Siswa. Al-Jabar: Jurnal Pendidikan Matematika, 6(2), 121-130.

Anggraeni, V., \& Wasitohadi, W. (2014). Upaya Meningkatkan Keaktifan Dan Hasil Belajar Matematika Siswa Kelas 5 Melalui Model Pembelajaran Kooperatif Tipe Teams Games Tournament (Tgt) Di Sekolah Dasar Virgo Maria 1 Ambarawa Semester Ii Tahun Pelajaran 2013 2014. Satya Widya, 30(2), 121-136.

Ariskasari, D., \& Pratiwi, D. D. (2019). Pengembangan Modul Matematika Berbasis Problem solving pada Materi Vektor. Desimal: Jurnal Matematika, 2(3), 249-258.

Azmi, M. (2016). Pengembangan Mobile Learning Sebagai Alternatif Media Pembelajaran di Masa Depan. Prosiding Seminar Nasional Teknologi Pendidikan.

Branch, R. M. (2009). Instructional design: The ADDIE approach (Vol. 722). Springer Science \& Business Media.

Charissudin, A. C. (2021). Pengembangan Media Pembelajaran Matematika dengan Animasi Menggunakan Aplikasi Swishmax. Square: Journal of Mathematics and Mathematics Education, 3(1).

Efiani, E. (2014). Kedudukan Koperasi dalam Hubungan Ekonomi Bangsa. JURNAL EKONOMI, 16(1), $123-131$.

Ekawati, T., Anggoro, B. S., \& Komarudin, K. (2019). Pengembangan Modul Pembelajaran Matematika Pada Materi Statistika Terintegrasi Nilai-Nilai Keislaman. AKSIOMA: Jurnal Program Studi Pendidikan Matematika, 8(1), 184-192.

Finariyati, F., Rahman, A. A., \& Amalia, Y. (2020). Pengembangan Modul Matematika Berbasis Etnomatematika Untuk Meningkatkan Kemampuan Pemecahan Masalah Siswa. MAJU: Jurnal Ilmiah Pendidikan Matematika, 7(1).

Haryanti, F., \& Saputro, B. A. (2016). Pengembangan Modul Matematika Berbasis Discovery Learning Berbantuan FlipBook Maker Untuk Meningkatkan Kemampuan Pemahaman Konsep Siswa Pada Materi Segitiga. Kalamatika: Jurnal Pendidikan Matematika, 1(2), 147-161.

Ismaniati, C. (2010). Penggunaan teknologi informasi dan komunikasi dalam peningkatan kualitas pembelajaran. Yogyakarta: Universitas Negeri Yogyakarta.

Izzatul Mufidah, C. (2014). Pengembangan Modul Pembelajaran Pada Kompetensi Dasar Hubungan Masyarakat Kelas X APK 2 di SMKN 10 Surabaya. Jurnal Administrasi Perkantoran (JPAP), 2(2).

Komarudin, K., Suherman, S., Puspita, L., \& Savitri, I. A. (2020). Electronic Magazine Development in Mathematics Learning. JTAM (Jurnal Teori dan Aplikasi Matematika), 4(2), 97-106.

Kurniati, A. (2016). Pengembangan modul matematika berbasis kontekstual terintegrasi ilmu keislaman. AlKhwarizmi: Jurnal Pendidikan Matematika dan Ilmu Pengetahuan Alam, 4(1), 43-58.

Mardiah, S., \& Rinaldi, A. (2018). Pengembangan Modul Pembelajaran Matematika Berbasis Etnomatematika Menggunakan Metode Inkuiri. Desimal: Jurnal Matematika, 1(2), 119-126.

Muhtadi, A. (2016). Pemanfaatan teknologi informasi dan komunikasi (tik) dalam pendidikan karakter di sekolah. Universitas Negeri Jogjakarta. 
Putra, F. G. (2018). Pengembangan Media Pembelajaran Berbantuan Software Swishmax pada Bahasan Bangun Ruang Sisi Datar. AKSIOMA: Jurnal Matematika dan Pendidikan Matematika, 9(2), $72-83$.

Putra, R. W. Y., \& Anggraini, R. (2016). Pengembangan Bahan Ajar Materi Trigonometri Berbantuan Software iMindMap pada Siswa SMA. Al-Jabar: Jurnal Pendidikan Matematika, 7(1), 39-47.

Ratnawati, D., \& Fitri, A. (2020). Pengembangan multimedia pembelajaran matematika dengan swishmax. Jurnal Inovasi Pendidikan Matematika (JIPM), 2(1), 32-40.

Rimadhona, S. I. (2010). Perancang Aplikasi multimedia Interaktif pada Salon Cantiq Skin and Body Care di Yogyakarta. Naskah Publikasi.

Rizkiah, A. W., Nasir, N., \& Komarudin, K. (2018). LKPD Discussion Activity Terintegrasi Keislaman dengan Pendekatan Pictorial Riddle pada Materi Pecahan. Desimal: Jurnal Matematika, 1(1), 3947.

Rodiawati, H., \& Komarudin, K. (2018). Pengembangan E-Learning Melalui Modul Interaktif Berbasis Learning Content Development System. Jurnal Tatsqif, 16(2), 172-185.

Rohmaini, L., Netriwati, N., Komarudin, K., Nendra, F., \& Qiftiyah, M. (2020). Pengembangan Modul Pembelajaran Matematika Berbasis Etnomatematika Berbantuan Wingeom Berdasarkan Langkah Borg And Gall. Teorema: Teori Dan Riset Matematika, 5(2), 176-186.

Shodikin, A. (2017). Pengembangan Bahan Ajar Kalkulus Integral Berbasis Animasi. Aksioma: Jurnal Program Studi Pendidikan Matematika, 6(1), 1-11.

Siregar, S. (2013). Meningkatkan Pemahaman dan Hasil Belajar Siswa Pada Mata Pelajaran Matematika dengan Menggunakan Software Graphmatica. Edumatica: Jurnal Pendidikan Matematika, 3(01).

Supriyadi, U. D. (2016). Pelaksanaan BOS dan minat masyarakat mengikuti pendidikan dasar gratis. Jurnal Ilmu Pendidikan, 17(1).

Suryadi, B. (2017). Pendidikan karakter: Solusi mengatasi krisis moral bangsa. Nizham Journal of Islamic Studies, 3(2), 71-84.

Utami, T. N., Jatmiko, A., \& Suherman, S. (2018). Pengembangan Modul Matematika dengan Pendekatan Science, Technology, Engineering, And Mathematics (STEM) pada Materi Segiempat. Desimal: Jurnal Matematika, 1(2), 165-172.

Vejvodova, J. (2015). The ADDIE model: Dead or alive. Department of Czech Language and Literature, Institute of Lifelong Learning, University of West Bohemia.

Wagiran, W. (2008). Pengembangan Media Pembelajaran Berbantuan Komputer Dalam Mendukung Perkuliahan Metrologi. Jurnal Kependidikan: Penelitian Inovasi Pembelajaran, 38(2).

Wahyuningsih, T., \& Rezeki, S. (2013). Perbandingan Hasil Belajar Matematika Siswa Melalui Penerapan Model Pembelajaran Langsung Dengan Pembelajaran Kooperatif. Jurnal Matematika, 3(2), 1693 1394.

Zulfikar, R. N., \& Tamrin, M. (2019). Pengembangan Modul Matematika dengan Pendekatan Metakognitif untuk Memfasilitasi Kemandirian Belajar Siswa SMK Muhammadiyah Kupang. ANARGYA: Jurnal Ilmiah Pendidikan Matematika, 2(2), 70-74. 